\title{
EL INFORME VALLES: LOS DESDIBUJADOS LÍMITES \\ DEL ARTE DE BOTICARIOS A FINALES \\ DEL SIGLO XVI (1589-1594)
}

\author{
Mar Rey Bueno \\ Facultad de Farmacia, Universidad Complutense, Madrid
}

\section{RESUMEN}

Análisis del origen, causas, desarrollo y consecuencias de la ordenanza del Protomedicato de 1591, destinada a regular aspectos fundamentales del arte de boticarios tales como el sistema de pesas y medidas, la elaboración de aguas destiladas y la correcta preparación de compuestos habituales.

PALABRAS CLAVE: España, boticario, sanidad, Francisco Valles, siglo XVI.

\section{SUMMARY}

Analysis of the origin, causes, development and consequences of the 1591 Protomedicato decree, destined to regulating fundamental aspects of the art of apothecaires such as the system of weights and measures, the distilled waters elaboration and the correct habitual compound preparation.

KEY WORDS: Spain, apothecary, health, Francisco Valles, $16^{\text {th }}$ century.

El 4 de diciembre de 1589 el pregonero de la Corte Matías de Santa Cruz anunciaba, en las principales calles y plazas de la villa madrileña, el último acuerdo del Protomedicato en materia sanitaria: la prohibición de usar aguas destiladas en alambiques de plomo o estaño, la instauración definitiva del marco castellano como medida única en las boticas, así como una serie de disposiciones relativas a la perfecta elaboración de los medicamentos usuales ${ }^{1}$. Se trataba del punto de inflexión en una disputa que mantuvo el máximo órgano sanitario de la monarquía hispánica con el gremio de boticarios de la villa y corte. Disputa que tiene su origen en las muchas lagunas legales que caracterizaban la práctica farmacéutica y que debe ser enmarcada en el paréntesis temporal que va desde 1588 a 1593 , fechas protagonistas de las dos

1 Archivo Municipal de Burgos (AMB), Sección Histórica (SH), S.J./4-1, ff. 14-14vº. 
grandes pragmáticas que habrían de gobernar los designios del Protomedicato durante todo el siglo XVII.

Lo que pudiera parecer un simple asunto local, circunscrito a la villa y corte madrileña y centrado en la práctica diaria de un colectivo científico tan poco considerado como el de los boticarios, constituye un ejemplo singular que permite analizar el proceso evolutivo de la legislación sanitaria renacentista, desde simple auto del Protomedicato hasta Real Ordenanza, a la vez que demuestra el escaso margen de actuación de una institución como el Real Tribunal del Protomedicato quien, pese a las amplias atribuciones conferidas por la Corona, veía limitadas sus actuaciones a la corte y cinco leguas alrededor.

La Real Ordenanza de 1591, más conocida como la ordenanza de Valles relativa a aguas destiladas, pesas y medidas de botica, venía a reglamentar un universo concreto, el de los preparadores de medicamentos, desprovisto de un protocolo de actuación y marginado de las aulas universitarias pero con una marcada evolución a lo largo de más de un siglo, merced a la publicación de los primeros tratados específicos sobre técnica farmacéutica, que venían a cubrir los vacíos legales existentes en la materia, y a la culminación de una simbiosis largamente gestada, la aplicación de prácticas alquímicas a la elaboración de medicamentos. Ambas circunstancias aparecen reflejadas en la ordenanza de 1591, que bien puede considerarse en la línea de las Instituciones que Luis Mercado (1520-1606), sucesor de Francisco Valles a la cabeza del Protomedicato, diseñó para médicos, cirujanos y algebristas en los últimos años del siglo ${ }^{2}$. La Real Ordenanza de 1591 regulaba, por vez primera, qué método de ejercicio habían de seguir los boticarios en el ejercicio práctico de su arte. Esta labor legislativa habría culminado de haberse hecho realidad la Real Pragmática de 1593, uno de cuyos puntos establecía la elaboración de una farmacopea general, que se habría transformado en la más destacada de su tiempo, al unificar la preparación de medicamentos en un área tan amplia como los reinos de Castilla, extendidos por buena parte del continente europeo y toda la zona americana.

2 MERCADO, L. (1594), Institutiones medicae iussu regio factae pro medicis praxi examinandis (...) in duos libros dissectae et à caeteris protomedicis approbatae, Madrid, Luis Sánchez; MERCADO, L. (1594), Institutiones chirurgicae iussu regio factae pro chirurgis in praxi examinadis (...) in duos libros dissectae \& a caeteris protomedicis approbatae, Madrid, Luis Sánchez y MERCADO, L. (1599), Institvciones que sv Magestad mando hazer al Doctor Mercado su Medico de Camara, y Protomedico general, para el aprouechamiento y examen de los Algebristas En las quales se declaran las diferencias que ay de coyunturas, y los modos que puede auer de desconcertarse Assi mismo, como se pueden y deuen reduzir a su figura y lugar. Y vltimamente se trata de los huessos quebrados y de su curacion, Madrid, en casa de Pedro Madrigal. 


\section{EL PREPARADOR DE MEDICAMENTOS EN LA LEGISLACIÓN RENACENTISTA}

Desde la Baja Edad Media la elaboración de medicamentos quedó encomendada a un grupo de profesionales, los boticarios, caracterizados por una formación empírica donde la tradición oral y el aprendizaje artesanal fueron determinantes. La falta de una instrucción institucionalizada, que suministrase personas formadas en el oficio para cubrir las necesidades de la población, se vio parcialmente subsanada por la publicación, desde mediados del siglo XV, de una literatura técnica especializada, encaminada a explicar los diversos aspectos de la profesión: las características que había de tener un boticario, las lecturas que debían nutrir sus años de ejercicio así como las técnicas dedicadas a una correcta preparación de medicamentos. Esta literatura, surgida en Italia, pronto fue traducida al castellano, a la par que comenzaban a publicarse en Castilla y Aragón textos escritos por boticarios afincados en ambos reinos ${ }^{3}$.

Desde los siglos XIV y, especialmente, XV el poder político comenzó a dictar una serie de medidas destinadas al control social de la práctica de herbolarios, especieros y boticarios. Se trata de oficios que debían ser vigilados por los llamados alcaldes y examinadores de médicos y cirujanos, tanto en el ámbito real como en el municipal. Los Reyes Católicos, a finales del siglo $\mathrm{XV}$, ya intentaron controlar el mercado del medicamento, pretendiendo que girara en torno a los boticarios examinados, atajando la venta ambulante en ferias por parte de drogueros ${ }^{4}$. Para ello se necesitaban dos medidas inmedia-

3 El primer libro específico conocido escrito para boticarios fue el Compendium Aromatariorum del médico salernitano Saladino de Ascolo, publicado por vez primera en Bolonia en 1488 y que sería adaptado al castellano por Alonso Rodríguez de Tudela (Valladolid, 1515). En la Península, el primer tratado farmacéutico conocido escrito por un boticario será el Examen apothecariorum (1521) de Pere Benet Mateu, seguido del Manipulus medicinarum (Salamanca, 1523) de Fernando Fernández de Sepúlveda y el Modus faciendi cum ordine medicandi de Bernardino de Laredo (Sevilla, 1527). Para entender la práctica farmacéutica durante la Baja Edad Media y los inicios del Renacimiento resulta imprescindible la consulta de GARCÍA BALLESTER, L. (2001), La búsqueda de la salud. Sanadores y enfermos en la España Medieval, Barcelona, Península-CSIC, pp. 561-644.

4 «Las cosas en que Sus Altezas han de mandar proveer que tocan cerca los fysycos y voticarios de sus reynos para que en lo uno y en lo otro se eviten muchas faltas y errores por donde muchos basallos de sus reybos pereçen». Memorial conservado en el Archivo General de Simancas (AGS), Diversos de Castilla, leg. I, doc. 55 y 56 y que fue estudiado por VILLA, I. (1939), Los médicos y la medicina en la época de los Reyes Católicos. Comentarios a unas ordenanzas del siglo XV, reproducidas del Archivo de Simancas, Valladolid, pp. 43-46. Se desconoce el autor de estas propuestas, así como las consultas que provocó, si bien merecen 
tas: el examen de boticarios, como requisito imprescindible para poder ejercer su arte; y la visita regulada de boticas establecidas, esencial para controlar la buena elaboración de medicamentos.

Ambas circunstancias aparecen contempladas en las Cortes de Valladolid de 1523, primeras que modifican sustancialmente la organización del Protomedicato, y cuya consecuencia más importante es el acuerdo establecido entre el monarca y los representantes de las ciudades para admitir una doble jurisdicción en cuanto al control de las profesiones sanitarias: por un lado, los protomédicos, cuyo ámbito de acción se circunscribía a la corte y cinco leguas alrededor; por otro, la justicia municipal, encargada de hacer cumplir las normas emanadas del monarca en materia sanitaria ${ }^{5}$. Es en esta fecha cuando se establece la forma de visitar las boticas y quienes son los encargados de llevarlo a cabo: los protomédicos, en la corte y cinco leguas alrededor; los corregidores o justicias ordinarios, con dos regidores y un físico aprobado, en el resto de la corona ${ }^{6}$.

Cuarenta años después, serán las Cortes de Madrid las encargadas de corregir los desórdenes y excesos observados por todos aquellos que se han dedicado a curar sin estar examinados. Para ello, se estipulan las características a presentar por médicos, cirujanos y boticarios que pretendan examinarse. En el caso concreto de estos últimos

«Mandamos (...) que no sean admitidos a examen, si no supieren latin, y no truxeren Testimonio autentico de cómo han practicado quatro años cumplidos con Boticarios examinados» ${ }^{7}$.

ser destacadas, tal y como ha hecho García Ballester en su estudio anteriormente mencionado. GARCÍA BALLESTER (2001), pp. 576 y 596.

5 El nacimiento y desarrollo del Tribunal del Protomedicato, así como la evolución legislativa a lo largo de su historia ha sido objeto de estudio de IBORRA IBORRA, Pascual (1885), «Memoria sobre la institución del Real Proto-medicato premiada en el concurso de 1884», Anales de la Real Academia de Medicina, 6, pp. 183-307, 387-418 y 496-532 [reeditado , con introducción e índice de Juan Riera y Juan Granda-Juesas, por el Secretariado de Publicaciones de la Universidad de Valladolid (Valladolid, 1987)]; MuÑoz GARRIDO, R. y MuÑIz FERNÁNDEZ, C. (1969), Fuentes legales de la medicina española (siglos XIII-XIX), Salamanca, Universidad; LÓPEZ TERRADA, Ma L. Y MARTíNEZ VIDAL, A. (coords.) (1996), «El Real Tribunal del Protomedicato en la Monarquía Hispánica, 15931808», Dynamis, 16, pp. 17-259 y CAMPOS DíEZ, Ma S. (1999), El Real Tribunal del Protomedicato Castellano (siglos XIV-XIX), Cuenca, Universidad de Castilla-La Mancha. Las normas emanadas de esta institución fueron recogidas por Miguel EUGENIO MUÑOZ (1751), Recopilación de las leyes, pragmáticas, reales decretos y acuerdos del Real Protomedicato hecha por encargo y dirección del mismo Real Tribunal, Valencia, Imprenta de la Viuda de Antonio Bordazar.

6 CAmpos DíEz (1999), p. 54.

7 MuÑOZ (1751), p. 155. 
Las mismas cortes madrileñas serán las encargadas, en 1576, de ampliar los requisitos solicitados a los boticarios que se presenten a examen, ampliando la práctica en botica a seis años y fijando la edad mínima para poder examinarse en 25 años. Asimismo, establece como prerrogativa que los boticarios asistentes al examen no queden sujetos a visita de sus boticas por los protomédicos, sino por el Consejo Real ${ }^{8}$.

Será la pragmática de 11 de noviembre de 1588 la que aborde, con propósito renovador, la organización y actuación del Protomedicato, a fin de revestir con mayores y más eficaces garantías la institución. En cuanto a los exámenes de profesionales sanitarios, vuelve a establecer los requisitos previos que se habían ido engrosando a lo largo del siglo. En el caso particular de los boticarios, se estipula que los protomédicos y examinadores no admitan a examen a ningún boticario que no sepa latín, que no presente acreditación de su práctica durante, al menos, cuatro años con boticario examinado y que no tenga 25 años cumplidos. Se trataba de un examen eminentemente práctico, realizado en la botica del Hospital General o del de la Corte, en presencia de dos examinadores y un boticario examinado. La prueba consistía en el examen de los simples y compuestos según los Cánones de Mesué, así como el modus faciendi ${ }^{9}$. En esta pragmática también se estipulaba la forma de realizar las visitas de botica, recogiendo lo ya aprobado por las Cortes de Valladolid en $1523^{10}$.

\section{LA VISITA DE BOTICAS DE 1589}

Uno de los artífices de la pragmática de 1588, primera de las dos grandes medidas legislativas del Protomedicato durante el gobierno de los Austrias, fue Francisco Valles, entonces protomédico de Felipe II y uno de los médicos más influyentes en la práctica sanitaria de la segunda mitad del XVI.

Burgalés de nacimiento, Francisco Valles se formó como médico en Alcalá, donde llegó a ser catedrático de Prima de la Facultad de Medicina. Entró al servicio real en 1572, como médico de cámara de Felipe II, y en 1584, por fallecimiento de Diego Santiago Olivares, fue nombrado protomédico de Castilla, dignidad que detentó hasta el año de su muerte (1592). En los años previos a su llegada a la corte escribió numerosos tratados médicos, centrados en comentarios a las obras de Galeno e Hipócrates, que alcanzaron gran difusión e influencia gracias a las setenta y dos reediciones que se hicieron en diversos

\footnotetext{
8 MuÑoz GARRIdO y MuÑIZ FERNÁNDEZ (1969), pp. 40-41 y 187-188.

9 MUÑOZ (1751), pp. 155-157.

10 MuÑOZ (1751), pp. 187-190.
} 
países europeos. Fue una de las máximas figuras del llamado galenismo hipocratista, caracterizado por una observación clínica objetiva como base de la medicina. Su gran reputación como intelectual hizo que fuese elegido por Felipe II, junto a Arias Montano y Ambrosio Morales, para formar la Biblioteca de San Lorenzo de El Escorial ${ }^{11}$.

Las numerosas normas que, en materia sanitaria, vieron la luz durante el mandato de Valles al frente del Protomedicato demuestran el interés manifiesto del médico por regular las profesiones vinculadas al arte de curar. Dispuesto a cumplir la nueva pragmática, organizó la visita de las boticas situadas en su radio de acción como protomédico, visita que sería problemática desde sus inicios y cuyos resultados finales nadie habría sido capaz de vislumbrar.

Se desconoce la fecha exacta en que dio comienzo la visita de las boticas madrileñas por parte del protomédico Francisco Valles y los examinadores de su tribunal, doctores Martín de Azpeytia y Andrés Bermejo y licenciado Lázaro de Soto. Las fechas en las que comenzaron a aparecer las primeras medidas emanadas de la mencionada visita permiten suponer que ésta se inició en los primeros meses del año 1589. Lo que había empezado como una visita rutinaria fue transformándose, con el paso de los meses, en un enfrentamiento abierto entre protomédico y boticarios. Así parecía vislumbrarse por diversos documentos aparecidos en años posteriores. La confirmación de esta disputa aparece en un memorial, desconocido hasta la fecha actual, redactado por los boticarios madrileños a comienzos del año 1590 y que permite seguir, paso a paso, las diversas actuaciones del Protomedicato.

Bajo el título Memorial y apuntamientos de las causas y razones que se dan por la parte de la congregacion de los Boticarios de la corte del Rey nuestro Señor, para que no se de lugar a hazer novedad en lo que siempre se ha acostumbrado ${ }^{12}$, se recogen las opiniones que suscitaron entre los botica-

11 LóPez PIÑERO, J. M. (1983), «Francisco Valles», en: Diccionario histórico de la ciencia moderna en España, Barcelona, 2 vols., 2, pp. 391-394. También resulta interesante la abundante bibliografía que, sobre el autor y su obra, se recopila en LÓPEZ PIÑERO, J. M. (1994), «Las ediciones de Controversiarum Medicarum et Philosophicarum libri decem de Francisco Valles», en: Historia y medicina en España. Homenaje al Profesor L. S. Granjel, Valladolid, Consejería de Cultura y Turismo, pp. 77-89.

12 Memorial y apuntamientos de las causas y razones que se dan por la parte de la congregacion de los Boticarios de la Corte del Rey nuestro Señor, para que no se de lugar a hazer novedad en lo que siempre se ha acostumbrado: ni se devan guardar los ocho capitulos y proveymientos que nuevamente pretenden introduzir, el Doctor Francisco de Valles Protomedico, y el licenciado Lazaro de Soto, el Doctor Martin de Azpeytia, y el Doctor Andres Bermejo, examinadores por el Rey nuestro Señor; sobre que se muden las pesas y medidas que se usan en las boticas, y aguas destiladas, y la trituracion de los medicamentos expurgantes y estomaticos, 
rios madrileños las diversas medidas emprendidas por Francisco Valles a lo largo de tres autos del Protomedicato. El primero de ellos, fechado en Madrid en 4 de mayo de 1589, se refería exclusivamente a la forma de destilar las aguas medicinales de dispensación en boticas:

«[El protomédico y los examinadores] mandaron que se notifique a todos los Boticarios desta Corte que de aquí adelante las aguas que en sus boticas se recepten, y vendieren, que ayan de ser para tomadas por la boca no sean distiladas por alquitaras de cobre, y las saquen, y distillen por alambiques de vidrio in valneo Marie; y que mientras se proveen de las dichas aguas, o no pudieren tener cantidad dellas, se den por las que en el entretanto se receptaren cozimiento de las mismas cosas: y que en caso que se pidan con tanta priessa que no aya lugar de sacarlas del dicho cozimiento se eche agua comun, o lo den sin agua para que en casa del enfermo se la echen. Y se manda, que quando dieren el xarave solo, o con agua comun, lo baxen del precio y lo cumplan assi, so pena de seys mil maravedis a cada uno que lo contrario hiziere» ${ }^{13}$.

Más completo es el segundo auto emanado del Protomedicato, fechado en 14 de septiembre de $1589^{14}$. Comienza indicando los motivos de su aparición:

«Por quanto aviendo por nra. persona [Francisco Valles], y de los dichos Examinadores, visitado todas las Boticas desta Corte, y las de los lugares de su jurisdiccion este presente año de mil y quinientos y ochenta y nueve, y aviendo de la dicha visita resultado muchos inconvenientes acerca de los pesos y medidas, y del modo de triturar los compuestos, assi para hazer pildoras como otros medicamentos expurgantes, y otras cosas, que de la dicha visita resultaron de que se siguian grandes daños e inconvenientes» ${ }^{15}$.

que Galia se a de hechar en el electuario rosado de Mesue, si en el Philonio Persico de Mesue se a de echar Piper o Papaver, que Turbit se a de gastar, que recepta de Benedicta se a de hazer, si la Esula usual es verdadera. Los quales capitulos y proveymientos son los que yran a lo ultimo despues de los apuntamientos: a cerca de los quales y cada uno dellos se advierte lo siguiente: por lo qual se entendera claramente que no conviene dar lugar a que se haga la dicha novedad, porque della resultarian muchos daños e inconvenientes, variedad y confusion en perjuyzio de la salud universal de la republica, s.a.; s.i.; s.f. [c. 1590]. Se trata de un documento formado por 29 folios. Los 23 primeros se dedican a exponer las razones que tienen los boticarios contra los autos dictados por Francisco de Valles y el Protomedicato que él representaba. Los seis últimos recogen los autos originales del Protomedicato. La única copia conocida, hasta el momento actual, se encuentra en Burgos: $A M B, S H$, S.J.-4/1.

$13 A M B, S H$, S.J.-4/1, fol. $12 \mathrm{v}^{\mathrm{o}}$.

$14 A M B, S H$, S.J.-4/1, ff. 13-14.

$15 A M B, S H$, S.J.-4/1, fol. 13. 
para pasar a describir los inconvenientes señalados y la necesidad de promulgar decretos que los remediasen, normas que serían de obligado cumplimiento por parte de los boticarios madrileños desde comienzos del año 1590 .

¿Cuáles eran esos inconvenientes? Se van describiendo a lo largo de ocho puntos. El primero de ellos se refiere a los pesos utilizados en botica, que habrán de ajustarse al marco castellano

«por tener averiguado que fueron estos los pesos de que usaron los Autores de los medicamentos que ay en la botica, assi Griegos como Arabes, hasta los Salernitanos, que por abuso introduxeron la particion de onça en nueve drachmas, y escrupulo en veynte granos: la qual corrompe la proporcion de los simples, que es quitar su ser y propia virtud a los compuestos» ${ }^{16}$.

Sigue, a continuación, con las medidas a usar en botica para agua, aceite y miel, estableciendo el uso de la onza común empleada para el jarabe y estipulando que, con la finalidad de mantener la limpieza necesaria, se tendrán tres medidas iguales, una para cada uno de los líquidos mencionados.

Vuelve al tema de las aguas destiladas, incorporando una serie de novedades respecto al auto anterior:

«mandamos que ningun Boticario, ni otra persona, no venda ningunas aguas de las que son para bebidas por la boca, ni dadas con xaraves, que sean sacadas por alquitara, ni con fuego seco, porque siempre de mas de la ignicion se cobra calidad de cardenillo, o alvayalde, sino que sean sacadas todas las dichas aguas que assi gastaren por alambiques de vidrio in valneo Mariae, y no pudiendo los dichos Boticarios tener copia de las dichas aguas, mandamos por ellas gasten cozimientos de las mismas cosas» ${ }^{17}$.

El siguiente punto se refiere a la perfecta preparación de los compuestos a través de una buena trituración y posterior mezcla, con la finalidad de obtener un medicamento homogéneo, pues se ha observado que

«de un mismo bote de electuario no purga nada, y otro de la misma cantidad y massa y bote hazen super purgacion o una disenteria» ${ }^{18}$

$16 A M B, S H$, S.J.-4/1, fol. 13. El sistema salernitano se diferenciaba del romano en que su base era decimal y la onza equivalía a un peso de nueve dracmas y no ocho, como en el romano. La alteración que comportaban los ponderales salernitanos no era grande en cuanto a pesas pequeñas, aumentando notoriamente en las pesas mayores.

$17 A M B, S H$, S.J.-4/1, fol. $13 v^{\circ}$.

$18 A M B, S H$, S.J.-4/1, fol. $13 \mathrm{v}^{\circ}$. El tema de la trituración de simples es ampliamente tratado por todos los autores farmacéuticos de la época, al ser uno de los aspectos más destacados del arte 
Los últimos cuatro puntos se dedican a diversas preparaciones habituales en el quehacer diario del boticario, como el electuario rosado de Mesué, el filonio pérsico, el turbit o la benedicta, que deben ser elaboradas siguiendo las nuevas indicaciones del protomédico.

Termina el auto señalando que todos los capítulos en él contenidos son de obligado cumplimiento para los boticarios de la corte y fuera de ella:

«y para que dello no puedan pretender ignorancia, les mandamos tengan un traslado dellos signado de nuestro secretario, para que assi ellos, como los officiales, que en sus boticas tuvieren, lo usen, sepan guardar y entiendan» ${ }^{19}$.

Ante la petición de los boticarios madrileños, el auto será confirmado en 13 de noviembre de $1589^{20}$ y pregonado en 4 de diciembre del mismo año.

\section{LA RESPUESTA DE LOS BOTICARIOS MADRILEÑOS AL AUTO DEL PROTOMEDICATO}

Las nuevas disposiciones del Protomedicato en materia farmacéutica no fueron del agrado de sus principales implicados, los boticarios madrileños. Podría pensarse que este gremio, nacido a la sombra de la todopoderosa institución sanitaria y carente de los privilegios que tenían otras congregaciones farmacéuticas españolas, se mostraría sumiso ante las cuantiosas modificaciones impuestas tras la visita de boticas de $1589^{21}$. Nada más lejos de la realidad. Desde los primeros momentos demostraron una fuerte cohesión y con-

de boticarios. Al respecto, y dada la contemporaneidad con los acontecimientos relatados, consultar OVIEDO, Luis de (1595), Methodo de la colección y reposicion de las medicinas simples, y de su correccion y preparacion. Va añadido el tercer libro: en el qual se trata de los letuarios, Xaraves, Pildoras, Trociscos, y Azeytes que estan en uso, Madrid, Luis Sánchez. En concreto, los capítulos XXV a XXXI del libro segundo (pp. 81vº-92), dedicados a esta temática.

$19 A M B, S H$, S.J.-4/1, fol. 14.

$20 A M B, S H$, S.J.-4/1, ff. $14-14 v^{\circ}$.

21 Frente a los poderosos gremios de boticarios característicos del Reino de Aragón, que autorregulaban su actividad profesional, científica y comercial, e incluso influían en la gobernación de las ciudades, el gremio de boticarios de Madrid era una institución débil, especialmente, tras las ordenanzas de 1552, promovidas por el ayuntamiento de la villa, que sometían absolutamente el ejercicio farmacéutico a un control exhaustivo y casi despectivo de los médicos, circunstancia ésta que situaba a los boticarios madrileños en el mismo nivel de preparación intelectual y técnica que especieros o tenderos de diversa índole. FolCH Jou, G. y PUERTO SARMIENTO, F. J. (1984), «Origen y evolución de las corporaciones farmacéuticas españolas», Atti e Memorie della Accademia Italiana di Storia della Farmacia, 1(2), pp. 1-19. 
ciencia de grupo que les hizo replicar, punto por punto, lo dispuesto por Valles en un extenso memorial ${ }^{22}$ que comenzaba señalando

«la variedad y confusion que han tenido en proveer y luego reponer algunos de los dichos capitulos» ${ }^{23}$.

y que fue presentado ante las Cortes de Castilla reunidas en Madrid en 1590 para evitar, en la medida de los posible, que el Consejo Real tramitase una nueva ordenanza con la que no se sentían de acuerdo

«En 10 de Enero de 1590 [...] Leyóse una petición en nombre de los boticarios desta Corte en que dicen, que el doctor Valles proveyó ciertos capítulos cerca del mudar las pesas y medidas que ha de haver en las boticas y mandado que se guarden, de los quales hacen presentación y también la respuesta que hacen a ellos, y que dello resultará notable daño a la república y a la salud de los naturales destos Reynos, y suplican que se salga a este negocio en nombre del Reyno por estar pendiente en el Consejo Real. Y haviendo votado sobre lo que se hará, salió por mayor parte que Francisco Diaz, don Francisco Guil, don Ladron de Guebara y don Diego de Orozco, vean estos papeles y se informen de las causas que hay en pro y en contra del negocio, de personas doctas y experimentadas, y se entienda del doctor Valles que le ha movido a hacer esto, y si fuere menester lo comuniquen con los letrados del Reyno, y hechas estas diligencias y las que mas les pareciere para entender lo que mas conviene, den quenta dello en el Reyno para proveer lo que se hubiere de hacer» ${ }^{24}$.

Los primeros aspectos a tratar se refieren, concretamente, a las modificaciones que tuvo que hacer el Protomedicato de sus primeras disposiciones, frente a las quejas y explicaciones presentadas por los boticarios ${ }^{25}$, para proseguir con los demás puntos objeto de debate, a saber, las pesas y medidas a emplear en botica, la forma de elaborar las aguas destiladas, la correcta trituración de los simples y la preparación de la galia y el filonio pérsico.

Todos ellos, excepción hecha del tema destilatorio, tienen un trasfondo común: la integridad y pureza de las fuentes antiguas frente al barbarismo y error de las traducciones medievales. No se puede olvidar que Francisco Valles es uno de los autores que mejor representa el espíritu de su época, asentado en el conocimiento filológico de las fuentes clásicas. Además de utilizar el recurso renacentista de la experiencia y la observación, Valles acude a los originales

$22 A M B, S H$, S.J.-4/1, ff. 1-12.

$23 A M B, S H$, S.J.-4/1, fol. 1.

24 Actas de las Cortes de Castilla, Madrid, 1886, tomo XI, p. 213.

25 Se refiere, en concreto, al mandato sobre la forma de elaborar la Benedicta y el Turbit a emplear. $A M B, S H$, S.J.-4/1, fol. 2. 
griegos, a los códices, para depurar los textos y ver lo que en realidad quería decir el autor ${ }^{26}$. Esta actitud se observa en todas las explicaciones utilizadas por el protomédico para aclarar el porqué de sus modificaciones, encaminadas a reestablecer la pureza que, para él, tienen las fuentes clásicas frente a las alteraciones incorporadas por árabes y salernitanos a lo largo de la Edad Media.

Esta posición queda de manifiesto en el primero de los puntos tratados, el relativo a pesas de botica. Frente a las razones esgrimidas por el protomédico para adoptar el marco castellano, acusando a los médicos salernitanos de introducir la onza de nueve dragmas en lugar de la tradicional de ocho, la respuesta de los boticarios parece de una lógica aplastante:

«que las pesas del marco Castellano no se puede dezir, que son aquellas de que usaron todos los autores de los medicamentos Griegos, Romanos, Latinos, y Arabes, porque no todos usaron de unas mismas pesas y medidas, autes por razon de ser de regiones diferentes tuvieron diferentes pesas y medidas» ${ }^{27}$.

De hecho, frente a los ataques de Valles a la modificación salernitana, los boticarios madrileños abogan por la Escuela Salernitana como la verdadera unificadora de las pesas farmacéuticas, adaptación que fue aceptada

«de todas las provincias de Italia, Francia, Alemania, España, y las demás que se tiene noticia, y se han usado despues aca, de mas de trecientos años a esta parte, con mucha aprovacion y buen sucesso, sin contradicion alguna» ${ }^{28}$.

para terminar señalando el perjuicio que, a su modo de ver, significaría la adopción del nuevo sistema:

«si agora se les mudassen las pesas, no se puede negar, sino que se harian grandes errores muy en daño de la salud de los hombres, porque ellos yvan con su costumbre (que es mala de perder) usando de sus Doses, que tienen practicadas y experimentadas, y darseles medicinas muy diferentes de su intento y proposito. Avria otro inconveniente, que se saca de lo de arria, que sise mudassen las pesas los medicos muy antiguos avrian menester tornar a practicar de nuevo, y esperimentar las medicinas hechas con nuevas pesas» ${ }^{29}$.

26 MonTero Cartelle, Enrique (2001), «El médico filólogo en el siglo XVI», en: GarCíA Hourcade, Juan Luis y Moreno Yuste, Juan Manuel (coords.), Andrés Laguna. Humanismo, ciencia y politica en la Europa renacentista, Valladolid, Junta de Castilla y León, pp. 93-121.

$27 A M B, S H$, S.J.-4/1, fol. $2 \mathrm{v}^{\circ}$.

$28 A M B, S H$, S.J. $-4 / 1$, fol. $3 v^{\circ}$.

$29 A M B, S H$, S.J. $-4 / 1$, fol. 5. 
Resulta curioso que ni protomédico ni boticarios hagan alusión a la medida tomada en 1513, según la cual, se ordenaba hacer las pesas de botica según las empleadas en Salerno, medida motivada por la gran diversidad de pesos detectada por los protomédicos de la época y que conducía a

«grand confusion e diversydad en las pesas de los boticarios con que pesan las medecinas y los compuestos dellas porque las hasen ellos mismos cada uno para sy e haziendolas como las hasen por granos de trigo, en unas partes son mayores e en otras menores, de lo qual se ha seguido e sygue muy grand daño» ${ }^{30}$.

Esta normativa se ratificó en 1543 por Carlos V quien, en un despacho dado al marcador real Juan de Ayala, ordenaba hacer las pesas de botica arregladas a las de Salerno ${ }^{31}$.

El tema de las aguas destiladas también es objeto de polémica, al no coincidir los argumentos esgrimidos por los boticarios con los ordenados en el auto del Protomedicato. Frente a la obligación de destilar en alquitaras de vidrio mediante baño María, los boticarios argumentan la fragilidad de esos vasos y la imposibilidad de destilar muchos de los simples empleados en botica, pues las temperaturas alcanzadas en el baño María son insuficientes para extraer las virtudes de muchos simples resinosos o leñosos:

«La distilacion del Valneo Mariae, seria buena para distilar algunas cosas de sustancia tenue y delicada, como las violetas y sus semejantes, que quieren un calor templado, como lo es el del baño, o para apartar por distilacion de la sustancia de alguna medicina alguna virtud solutiba, o superficiaria: pero no es bastante para sacar toda la virtud de las yervas, por ser el calor tan floxo, que no puede sacar mas que la humidad superflua de las yervas y alguna virtud superficiaria, dexandose la substancial, que es la de mas importancia para su conservacion y virtud de las aguas $\iota^{32}$.

Respecto a la trituración de los medicamentos, los boticarios se muestran inflexibles: para ellos, se trata de un mandato superfluo y que atenta contra el buen hacer y la profesionalidad del sector farmacéutico ${ }^{33}$.

Termina el memorial de los boticarios madrileños con las divergencias en cuanto a la preparación del electuario rosado de Mesué y el filonio pérsico, aspectos en los que, una vez más, vuelve a hacerse manifiesta la defensa de la

30 Herrero Hinojo, P. y Francés Causapé, Ma C. (1972), «Aportación al estudio de los ponderales farmacéuticos empleados en España», Boletín de la Sociedad Española de Historia de la Farmacia (BSEHF), 91, pp. 137-147.

31 Chiarlone, Q. y Mallaina, C. (1847), Ensayo sobre Historia de la Farmacia, Madrid.

$32 A M B, S H$, S.J.-4/1, fol. 7.

$33 A M B, S H$, S.J.-4/1, ff. $8-8 \mathrm{v}^{\circ}$. 
pureza de las fuentes de Valles frente al recurso de los boticarios de quienes, para ellos, son autoridades. En realidad, los boticarios no hacían, ni más ni menos, que seguir las indicaciones reflejadas en los textos que les servían en su práctica diaria ${ }^{34}$ y que, a falta de una legislación oficial, eran el único recurso para el ejercicio correcto de su arte.

\section{LA ORDENANZA SOBRE PESOS, MEDIDAS Y AGUAS DESTILADAS}

Pese a toda la actividad desplegada por el gremio de boticarios madrileños, el poder del Protomedicato era mayor y la cercanía de Francisco Valles a los círculos de poder cortesanos favorecieron que, tan sólo un año después, el Consejo Real aprobara la nueva ordenanza donde se recogían todos los puntos del auto pregonado a finales de 1589. Bajo el título de Memoria de los que esta ordenado por el doctor Valles... cerca del orden que han de guardar los boticarios... en los pesos y medidas y aguas destiladas y otras cosas ${ }^{35}$, la norma fue recogida en la Recopilación de $1640^{36}$ y, posteriormente, incluida en la recopilación de leyes exclusivas del Protomedicato, realizada por Miguel Eugenio Muñoz en $1751^{37}$. La reproducción se incorpora en el capítulo XIV, titulado «De las obligaciones de los Boticarios», y consta de cuatro títulos. El título V, dedicado a las aguas destiladas, obligaba a elaborar las aguas medicinales en alambique de vidrio y mediante baño María. El título VI, relativo a pesas y medidas, instituía el marco castellano como patrón obligatorio en todas las boticas. El título VII, por su parte, describíd el correcto modo de moler los medicamentos, mientras que el título VIII se dedicaba al filonio pérsico, la benedicta y el lectuario rosado. Lo que había nacido como una visita de boticas terminaba como una Real

34 Los Canones universales de Mesué, el Antidotarium Nicolai, el Liber servitoris de Albucasis, el De simplicibus medicinis de Serapión o el Liber pandectarum de Matteo Silvático, libros todos ellos recomendados por los principales autores médicos y farmacéuticos de la época y que, en el proyecto de ordenanzas de los Reyes Católicos comentadas en apartados anteriores, eran los textos explícitamente recomendados para el correcto ejercicio de la práctica farmacéutica. VILLA (1939), p. 50.

35 Un ejemplar de la misma puede consultarse en la Biblioteca Zabálburu (signatura 33116 bis). Otra copia se encuentra en el Archivo de la Catedral de Santiago de Compostela, citada por Clemente SAN Román, Y. (1992), Impresos madrileños de 1566 a 1625, Madrid, Universidad Complutense de Madrid.

36 Recopilacion de las leyes destos reynos hecha por mandado de la Magestad Catolica del rey D. Felipe Segundo... con las leyes que despues de la ultima impresión se han publicado por... don Felipe Quarto..., Madrid, Catalina de Barrio y Angulo y Diego Díaz de la Carrera, 1640, 3 vols. Existe una reproducción facsimilar (Valladolid, Lex Nova, 1982).

37 MUÑOZ (1751), pp. 177-178. 
Ordenanza de obligado cumplimiento no sólo por boticarios madrileños, sino por todo el colectivo farmacéutico que ejercía su labor en los reinos de Castilla.

Un año después de aprobarse tan polémica normativa, aparecía la última obra escrita por Valles, el Tratado de las aguas destiladas, pesos y medidas ${ }^{38}$, destinada a explicar los motivos y razones que llevaron al protomédico a seguir adelante pese al enfrentamiento manifiesto de todos los preparadores de medicamentos:

«porque en las averiguaciones que para estos dos puntos se hicieron huvo alguna dificultad, y diversidad de pareceres, me ha parecido conveniente cosa, recoger en un breve comentario, los fundamentos y razones que para hacer tal mudança huvo, y de camino responder a las dificultades ${ }^{39}$.

recordando a sus potenciales lectores que no era un capricho suyo, sino que la normativa venía avalada por los catedráticos de las principales universidades castellanas:

«Y quiero traer muchos autores en esto, aunque no es de mi costumbre, por ver si con confessar que es de otros muchos antes de mi, podria escusar la embidia, que contra mi se concitaria si yo dixesse que era invencion mia: lo qual no puedo dezir, pues han concurrido en este parecer, la mayor parte de las universidades de cuenta, y todos los [médicos] de Camara, y seis examinadores, y otros muchos muy doctos (...) Yo no soy tan mal acondicionado que pida, que el que no le entiende assi sea de mi parecer: mas pido, que el que no lo fuese no se tome conmigo, pues ay tantos con quien averlo que son del mismo parecer» ${ }^{40}$.

Pese a que la nueva norma constaba de cuatro puntos, son sólo dos los tratados por Valles en su obra, quizás los más polémicos, relativos a la forma de destilar aguas medicinales y el sistema ponderal a usar en las boticas. Ambos

38 VAlLES, F. (1592), Tratado de las aguas destiladas, pesos y medidas de que los boticarios deben usar por Nueva Ordenanza y Mandato de Su Majestad y Su Real Consejo, Madrid, Luis Sánchez. En la Biblioteca Nacional de Madrid se conserva un manuscrito, el 6184, anónimo y sin fecha pero cuyo contenido es muy similar al observado en esta última obra de Valles. Nos podríamos encontrar ante un borrador de la misma. Encuadernado con otros documentos de finales del siglo XVI, consta de tres partes: «Respuesta a lo que se dice contra lo proveydo açerca de las pesas de que se a de usar en la botica» (ff. 266-271); «Respuesta a lo que se dice contra las medidas que se mandan tener en las boticas» (ff. 271-273) y «Respuesta a la relacion que se nos dio de las razones que por su parte dizen los que contradicen nuestra determinacion en lo tocante a las aguas destiladas y pesos y medidas》 (ff. 274-281).

39 VALLeS (1592), pp. 3-3vo.

40 VAlles (1592), pp. $3 \mathrm{v}^{\mathrm{o}}-4$. 
aspectos iban a tener consecuencias inmediatas en el devenir de la profesión farmacéutica: por una parte, la acreditación de los boticarios como únicos expertos en la práctica destilatoria; por otra, la creación de una nueva institución sanitaria de indudable trascendencia en el presente y futuro de la profesión, la Real Botica, cuya aparición era consecuencia indirecta del enfrentamiento entre los boticarios madrileños y el protomédico Valles por el tema de las pesas y medidas ${ }^{41}$.

\section{DESTILACIÓN Y FARMACIA}

Las prácticas destilatorias, desarrolladas a lo largo de los siglos XIII y $\mathrm{XIV}$, se incorporaron al elenco de actividades técnicas propias de un boticario español desde comienzos del Renacimiento. Sirva como ejemplo lo comentado por Pere Benet Mateu cuando dice que

«destillatio sive sublimatio est per quam extrallitur virtus subtilis medicinarum»42.

De hecho, la inclusión de medicamentos elaborados por destilación, las famosas aguas destiladas, era moneda corriente en los recetarios bajomedievales que han llegado hasta nuestros días ${ }^{43}$. Pese a ser conocida desde la antigüedad, la destilación farmacológica sufrió una difusión espectacular durante los siglos XVI y XVII debido, en gran parte, a la publicación de obras dedicadas específicamente a la materia. Se consideraba una novedad en tanto en cuanto su práctica había quedado circunscrita al ámbito de la alquimia y a la preparación de medicamentos muy específicos. Así lo manifiesta Conrad Gesner, autor de uno de los tratados más difundidos sobre arte destilatoria, el Tesoro de los remedios secretos de Evónimo Filiatro, cuando dice:

41 Para una mayor información respecto a esta segunda consecuencia, consultar REY Bueno, M. (2002), Los señores del fuego. Destiladores y espagíricos en la corte de los Austrias, Madrid, Corona Borealis, pp. 91-115.

42 Benedictus Matheus, Petrus (1521), Liber in examen apothecariorum quam etiam adolescentium eruditionem a filio eiusdem predicti Petri Benedicti Mathei in lucem traditus incipit, Barchinone, Iohannis Rosembach, fol. 67.

43 Entre otros, el Recetario de Alba, colección de recetas de la Casa de Alba, o el Recetario de Enrique $I V$, amplia colección de recetas prescritas por los médicos reales al monarca Enrique IV, su familia y casa real, fechada en 1462. Ambos recetarios, junto al empleo de prácticas destilatorias en la España del siglo XV, son interesante objeto de estudio en GARCíA BALLESTER (2001), pp. 561-644. 
«Hay algunos que atribuyen el origen de extraer las aguas (como ellos las llaman), los licores y los aceites de los medicamentos simples, por la fuerza del fuego, a Hieronymus de Brunschwig que, hace unos setenta años, ejercía la medicina en Estrasburgo. Pero, en esto, se engañan completamente. Tal arte no fue inventado por él, sino que fue el primero que escribió sobre el tema en nuestra lengua alemana y lo divulgó» ${ }^{44}$.

La elaboración de medicinas por técnicas destilatorias partía de la extracción de los principios activos en medios alcohólicos. Para ello se dejaban macerar durante días los simples medicinales en espíritu de vino o aguardiente. A continuación se sometía al proceso destilatorio propiamente dicho: el resultado de la maceración se calentaba, las esencias extraídas por disolución en alcohol se volatilizaban y ascendían por el serpentín para acabar licuándose en el refrigerante y cayendo en forma de líquido sutil. Las sustancias así obtenidas recibían el nombre de aguas por su aspecto acuoso y podían ser, a grandes rasgos, simples, cuando se destilaba un único simple, o compuestas, cuando se destilaban dos o más simples. Todo este proceso requería la intervención de horno, elemento indispensable en cualquier laboratorio, y de diferentes vasos de vidrio, por ser éste el material más adecuado para retener los espíritus sutiles y, fundamentalmente, porque evitaban la contaminación de la muestra que se producía al emplear recipientes de estaño, plomo o cobre.

Esta contaminación era, precisamente, la que pretendía evitar el protomédico Valles, uno de los médicos españoles más avanzados en el conocimiento de la práctica destilatoria, no en vano actuaba como autoridad máxima de la sanidad regia filipina, caracterizada por la difusión de laboratorios de destilación y el empleo habitual de medicamentos químicos obtenidos por medios destilatorios ${ }^{45}$.

Las ideas defendidas por Valles en materia destilatoria ocupan la parte primera de su Tratado, que no es una obra de destilación al uso, sino una suerte de réplicas y contrarréplicas sobre las razones y fundamentos que llevaron al protomédico a modificar el tipo de destilación observada en las farmacias madrileñas.

Los aspectos tratados por Valles son dos: la mayor eficacia de la destilación en baño y la malignidad de las aguas obtenidas en recipientes de estaño y plomo. Como punto de partida, Valles manifiesta su opinión al respecto:

44 GeSNER, C. (1552), De remediis secretis, liber physicus, medicus et partiam chymicus et oeconomicus in villorum diversi apparatu, medicis \& pharmacopoiis omnibus praecipi necessariur nunc primun in lucem editus, Zurich. Existe una traducción española, publicada en 1996: MANRIQUe, Andrés y FernándeZ, Agustín, Tesoro de los Remedios Secretos de Evónimo Filiatro, San Lorenzo de El Escorial, EDES, de donde se ha extractado la cita (pp. 143-144).

45 Rey Bueno (2002), pp. 33-122. 
«ningunas [aguas] son buenas, sino las hechas en vidrio por baño (...) las de Alquitaras, ni huelen, ni saben a las cosas de que son, sino todas de una manera a humo: de tal manera, que esta agua comunes, como de borraxa, chicoria, llanten, hinojo, apio, y cosas semejantes, los mismos Boticarios no las distinguieran si las mudan los retulos: las quales todas siendo de baño se distinguen muy bien, de qualquiera que conozca las cosas de que son sacadas, y son claras, y sin humo» ${ }^{46}$.

para pasar, a continuación, a exponer los puntos de divergencia entre su forma de entender la destilación y la que tienen los boticarios madrileños. Frente al empleo de baño María como único método destilatorio, propuesto por Valles, los boticarios replican la poca fuerza de este sistema, incapaz de extraer la virtud de otros simples que no sean tenues hierbas, además de la poca duración observada en las aguas así destiladas, circunstancias a las que responde Valles

«Este dicho nace de poca esperiencia, por que vemos sacar por baño azeites gruessos, y las que llaman quintas essencias de maderos densissimos (...) si quisieren, en Madrid pueden aver visto las de baño, y de calabaça (...) de dos años sin corrupcion ninguna: y a lo menos passarlas de año en año es facilissimo, sabiendo las conservar en vaso y lugar idoneo, y trassegandolas en haziendo algun assiento, como hazen al vino: y es mas razon q. sino saben hazerlo, lo deprendan, pues es de su arte, q. no que porque no lo saben, lo vituperen $»^{47}$.

El empleo de vasos exclusivamente de vidrio suscita, una vez más, la controversia de los boticarios, quienes consideran que se trata de un material demasiado costoso, circunstancia que elevará el precio de las aguas, haciéndolas muy caras, o provocará todo tipo de fraudes, posiciones ambas que son replicadas por Valles, quien informa de la aparición de un nuevo destilatorio de vapor «tanto mas barato y facil, que lo sera tanto como las mas ruines alquitaras $\rangle^{48}$. Parece evidente que Valles se está refiriendo al aparato ideado por Diego de Santiago, destilador que trabajó en el montaje del soberbio laboratorio escurialense a finales de la década de los ochenta, labor que fue recompensada por Felipe II concediéndole una patente de invención y una exclusiva por diez años de un destilatorio por él ideado ${ }^{49}$.

Las razones argumentadas por Francisco Valles ya habían sido señaladas por otros autores contemporáneos. Así, el médico catalán Francisco Micón ${ }^{50}$ decla-

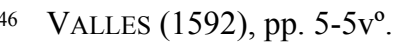

47 VALLES (1592), pp. 6 y $10 \mathrm{v}^{\mathrm{o}}-11$.

48 VALLES (1592), pp. 13-13vo.

49 ReY Bueno (2002), pp. 70-72.

50 Formado en la Facultad de Medicina de Salamanca, se trasladó tras su graduación a Guadalupe, con la intención de adquirir experiencia en sus renombrados hospitales. Fue en ellos 
raba, hablando de las aguas destiladas, que cualquier malignidad observada en su consumo procedía no de ellas mismas, sino de su incorrecta elaboración:

«de donde claramente se colige, quan dañoso es el plomo, y como del resulta alguna ponçoñosa qualidad la qual assi a el agua, como aun todos los otros, q. dentro de vasos de plomo, o de estaño mezclado con plomo, se conservan, comunica. De aquí entenderan, quan engañados estan los Boticarios todos, y aun todos los vulgares, que en todas sus alquitaras de cobre tienen el chapitel de plomo, y destillan por el todas las aguas cordiales, y no cordiales (...) y si algunos daños resultan alguna vez, de la bebida de algunas aguas destilladas, mas se ha de attribuyr, a la maligna qualidad que del plomo conçiben, que a otra qualquier cosa. Por tanto, yo tendria por mejor, que el chapitel fuesse de cobre, bien estañado, sino del mismo estaño, que no de plomo, o sino que fuessen todos los vasos, do se destillaria de vidrio, o a lo menos, dar decoctos con los xaraves y no aguas destilladas $\rangle^{51}$.

Lo cierto es que no existía un método común de destilación que fuese utilizado como patrón entre los boticarios. Así lo manifiesta Alonso de Jubera en su tratado sobre preparación de medicamentos

«Y assi la comun practica y orden en los desta profession es distilar todas las aguas por sus alembiques: aunque unos lo hazen (como mas curiosos que otros) procurando para lo hazer con mas perfecion y menos daño de lo que se ha de distilar, alembiques de vidrio, otros de tierra, otros de cobre muy estañados: unos con muy moderada brasa de carbon, otros con leña» ${ }^{52}$.

donde conoció a Francisco Hernández, entonces médico del monasterio extremeño, con quien realizó numerosas disecciones de cadáveres humanos además de acompañarle en sus excursiones botánicas. Al terminar su formación en Guadalupe fijó su residencia en Barcelona, donde dedicó el resto de su vida al ejercicio de la medicina así como el cultivo de la botánica, labor que le llevaría a estudiar la flora de las montañas catalanas y mantener una estrecha relación con el médico y naturalista francés Jacques Dalechamps. LÓPEZ PIÑERO (1983), 2, p. 61.

51 Micon, F. (1576), Alivio de los sedientos, en el qual se trata la necesidad que tenemos de bever, frio, y refrescado con nieve, y las condiciones que para esto son menester, y quales cuerpos lo pueden libremente suportar, Barcelona, Casa de Diego Galván, p. 56.

52 JUBERA, A. (1578), Dechado y reformacion de todas las medicinas compuestas usuales, con declaracion de todas las dudas en ellas contenidas, assi de los simples que en ellos entran y succedaneos que por los dudosos se hayan de poner, como en el modo de las hazer, Valladolid, Diego Fernández de Córdoba, p. $62 \mathrm{v}^{\mathrm{o}}$. Pese a dedicar un capítulo a las aguas destiladas (Cap. 68. En el qual succintamente se trata de las aguas, pp. 62-62 $\mathrm{v}^{\circ}$ ) no se muestra Jubera muy partidario de las mismas, pues ha observado en ellas cierto olor, color y sabor que nada tiene que ver con el agua pura. 
La polémica abierta entre el protomédico Valles y los boticarios madrileños no quedó circunscrita a la villa y corte. La nueva ordenanza de 1591 había de ser cumplida en todos los reinos de Castilla y tal era el celo del protomédico que, desde 1590, había habilitado a visitadores encargados de vigilar el cumplimiento de la ordenanza. Las quejas no tardaron en llegar a la corte, pues el protomédico no tenía potestad para realizar tales nombramientos, correspondiendo a los justicias de cada ciudad vigilar por el correcto cumplimiento de la ley. Fue necesaria una resolución real, fechada en 10 de mayo de 1594, encargada de anular las potestades de esos visitadores y destinada a mandar

«a los corregidores del reino que cada uno de su distrito haga guardar lo acordado en lo de los pesos, medidas y destilaciones de aguas; y el consejo repela la pretension de los boticarios, que suplican de lo que sobre esto está mandado, pues no conviene se haga pleito ordinario» ${ }^{53}$.

La problemática sobre pesas y medidas no era exclusiva de Madrid. Cada ciudad, incluso cada villa española, tenía sus propios ponderales y mensurales. En materia farmacéutica, éste era un problema planteado ya en las primeras obras publicadas por y para boticarios, y que seguía vigente en el período aquí estudiado. Sirva como ejemplo la obra Theorica y practica de boticarios $^{54}$, del fraile boticario Fray Antonio Castell, benedictino del monasterio de Nuestra Señora de Montserrat. Publicada el mismo año que el Tratado de Valles, dedicaba un apartado final al tema de los pesos y medidas ${ }^{55}$, circunstancia muy habitual en las obras específicas de técnica farmacéutica. Aunque no menciona la polémica que se estaba llevando a cabo en el Reino de Castilla, si refleja la confusión observada entre las medidas romanas y salernitanas:

«Yo se que la mayor parte destas provincias tienen opinion fundada con la autoridad de los dichos Salern. Saladino y Praepos. de componer el crupulo de veynte granos, y no de veynte y quatro según la doctrina de los mas estimados Griegos de los quales havemos aprendido todo lo que tenemos de bueno de la medecina, a los quales con muchos otros doctores modernos, yo me arrimo antes que a tales autores, y algunos ignorantes y obstinados boticarios, que no tienen gana de salir del

53 IBORRA (1884), pp. 42-43.

54 CASTEll, A. (1592), Theorica y practica de boticarios en que se trata de la arte y forma como se han de componer las confectiones ansi interiores como exteriores, Barcelona, Sebastián de Cormellas.

55 «Sumario y tratado de los pesos y medidas que aquí se ha hecho mencion», pp. $335 \mathrm{v}^{\circ}-342$. 
lazo de la ignorancia. Por que si ellos los siguen en el scrupulo y dragma porque no los siguen en la onça? Y la componen de nueve dragmas como ellos enseñan con sus mesmos metros?(aunque en esta provincia de Xathaluña bien se guarda la onça de nueve dragmas) $\rangle^{56}$.

proponiendo, a continuación, la necesidad de que se unifique el sistema ponderal a utilizar en las boticas, medida que debe ser llevada a cabo desde el Protomedicato, para evitar la gran confusión observada porque

«ay casi tanta diversidad dellas [de pesos y medidas] como ay Villas y si en ello no se pone alguna orden (como dizen que se ha començado) cierto es impossible poder atinar a ello» ${ }^{57}$.

en lo que parece una clara alusión a la ordenanza propuesta por Valles.

Si importante era la unificación de pesas y medidas, de esencial podría calificarse la necesidad de uniformar las múltiples recetas que sobre una misma preparación circulaban en las boticas. La falta de una farmacopea oficial, propuesta por la pragmática de 1593 pero que no fue una realidad hasta el siglo XVIII, deja a los boticarios en manos de los numerosos recetarios, antidotarios y tratados de técnica farmacéutica que existían desde la Baja Edad Media, así como las modificaciones y adiciones que se fueron publicando a lo largo de todo el siglo XVI. De ahí que en la ordenanza de 1591 también se hiciese referencia a la correcta forma de preparar, según Valles, algunos de los compuestos más habituales de las boticas. Tal es el caso del filonio pérsico, uno de los compuestos presentes en los Cánones de Mesué. La nueva ordenanza mandaba prepararlo con pimienta, frente a la adormidera reseñada en la receta tradicional. Las quejas de los boticarios madrileños se encaminaban hacia una supuesta equivocación de los protomédicos con el filonio de los griegos, elaborado con pimienta, diferente del filonio pérsico, de invención árabe, y que siempre se había elaborado con adormidera. Luis de Oviedo, uno de los boticarios madrileños más destacados de su época, incluyó esta disputa en la segunda edición de su Methodo de la colección y reposicion de las medicinas simples. Oviedo, tras comentar las diversas opiniones sobre la materia, concluye que uno de los problemas básicos reside en la confusión existente en los manuscritos conservados de Mesué, pues no queda claro si escribe papaver o piperis. Aparece, una vez más, el problema filológico anteriormente comentado. Pese a que Oviedo considera que el medicamento se había de preparar con adormideras, recoge la ordenanza de Valles:

\footnotetext{
56 CASTELL (1592), pp. 337-337 $\mathrm{v}^{\circ}$.

57 CASTELl (1592), p. 340.
} 
«de todo lo que tenemos dicho parece, que el Philonio Persico se tiene de componer con dormideras blancas, y no con pimienta blanca. Pero en onze dias del mes de Mayo del año noventa y uno, entre otras cosas que el Dotor Francisco de Valles medico de la camara del Rey don Felipe Segundo, nuestro Señor, y su Protomedico, ordeno, que guardassen los boticarios de este Reyno, fue una, que quien quisiesse tener compuesto el Philonio Persico, le compusiesse con pimienta blanca, y no con dormideras blancas. Por lo qual despues aca se compone con pimienta blanca, puesto que muchos medicos doctos tienen lo contrario, y las razones que tenemos dicho, a mi parecer lo pruevan bastantemente» ${ }^{58}$.

\section{RÉPliCA A VALLeS: El MANUSCRITO DE CASTRo MEdinilla}

La respuesta más contundente a las ideas destilatorias de Francisco Valles se encuentran en el manuscrito inédito de Juan de Castro Medinilla, boticario cordobés de principios del siglo XVII. Falto de la portada, la licencia inserta al final del manuscrito lo denomina Discursos de la vía particular y verdadero modo de destilar compuestos ${ }^{59}$, título que ha tomado la Biblioteca Nacional de Madrid, donde está depositado, para su catalogación.

Fechado en 1619 , se trata de un tomo en $4^{\circ}$, encuadernado en pergamino y dispuesto para ser impreso, aunque se desconoce la razón por la que quedó inédito. El único estudioso que le ha dedicado un monográfico, Sergio Caballero Villaldea ${ }^{60}$, tiene su propia teoría al respecto

«sospecho que debió ser por algún motivo de índole política, toda vez que, en el texto del libro, hace algunos ataques atrevidos a la labor del célebre doctor Francisco Valles, protomédico de Felipe II, y observo que casi todos ellos van señalados, al margen de la página, con rayas de tinta que indican atención, cuando menos» ${ }^{61}$.

teoría un tanto endeble, pues ya había transcurrido más de un cuarto de siglo desde que fuera publicado el Tratado de Valles y no vivía ninguno de los protagonistas de tal acontecimiento.

La obra está dividida en dos discursos, primero y segundo, subdivididos, respectivamente, en ocho y seis artículos o puntos. En el discurso primero se trata de la destilación en general, de la destilación de aguas y hierbas, de los

58 OviEdo (1595), p. 189.

59 Biblioteca Nacional (BN), mss. 4250.

60 Caballero Villaldea, S. (1948), Juan de Castro Medinilla y Pabón (Ilustre boticario cordobés del siglo XVII). Su vida. Sus obras, Madrid.

61 Caballero (1948), pp. 8-9. 
aparatos de destilación, de los materiales con que se construyen estos aparatos, de la forma de destilar y de recetas diversas. El discurso segundo se ocupa de la recolección, reposición y conservación de las hierbas y productos que han de destilarse y, además, de la conservación de las aguas destiladas.

Se trata del primer escrito de Castro Medinilla, realizado a la edad de veinticinco años, tal y como lo manifiesta al final de la obra ${ }^{62}$. Pese a su juventud, disfrutaba de gran influencia en el Tribunal de la Suprema Inquisición, siendo oficial de ella en Córdoba y relacionándose amistosamente con algunos destacados miembros de la misma que, por razones diversas, siempre aparecen mencionados en sus obras ${ }^{63}$.

Las referencias de Castro Medinilla a la obra de Valles se encuentran en el discurso primero, en concreto, en los puntos tercero y cuarto, dedicados a probar la benignidad del estaño en los alambiques de destilación ${ }^{64}$ y la antigüedad del uso de recipientes de vidrio en prácticas destilatorias ${ }^{65}$.

La ordenanza de Valles prohibía el empleo de recipientes estañados en la elaboración de aguas destiladas, objeto de réplica de Castro Medinilla. Casi todos los argumentos del boticario cordobés van en una misma línea: la falta de conocimientos prácticos del protomédico

«Bien entiendo que si el Doctor Valles hubiera distilado i cocido, usando de la practica i personalmente i por vista de sus ojos conociera que cosa sea sacar la virtud de las ierbas, dixera mui en contrario de lo que escribio por theorica i por oidas de los que no supieron como debian saber la transmutacion de la virtud de la substancia de la planta en el licor (...) Bien es verdad que en el modo que hiço los discursos ni vasos vidriados ni otros algunos puedan ser de provecho» ${ }^{66}$.

62 BN, mss. 4250, fol. 140.

63 Castro de Medinilla escribió cuatro obras en seis años. La primera fue el ya mencionado tratado de destilación, terminado en 1619. Un año después veía la luz la Historia de las virtudes $i$ propiedades del tabaco, $i$ de los modos de tomarle para las partes intrinsecas $i$ de aplicarle a las extrinsecas (Córdoba, Salvador de Cea Tesa, 1620). En 1623 escribió un Tratado sobre confectiones Alkermes, que debió quedar manuscrito. En 1625 publicaba una Censura general en la celebre composición del Ungüento de la condesa de Guillermo de Varignana (Córdoba).

64 Punto tercero: «Si el estaño es conveniente para la distilacion de cocimientos i que sea estaño» (BN, mss. 4250, ff. 29v $\left.\mathrm{v}^{\circ}-50\right)$.

65 Punto cuarto: "Razones $i$ authoridades, donde se declara el ierro de los que han usado $i$ usan vasos de vidrio de qualquiera modo para distilar las ierbas, i de la mala intelligencia de los lugares de donde fueron inventados» (BN, mss. 4250, ff. 50-83).

66 BN, mss. 4250, fol. 30 . 
Castro Medinilla se muestra contrario al empleo de alquitaras de plomo, si bien no comparte ese enfrentamiento con respecto a las de estaño. De cualquier forma, demuestra cómo el uso de alquitaras de plomo sigue estando plenamente vigente, un cuarto de siglo después de promulgada la ordenanza de Valles:

«en esta ciudad de Cordoba distilandose tanto azahar como se distila, es de grande admiracion un mes antes de el empeçar a distilar veer quanta cantidad de plomo falta de las alquitaras, pues no tienen otra cosa de mas ocupacion los caldereros que adereçar plomo para los desdichados que reciben aguas, pues si se hiciera el computo de el plomo que disminuien, fuera de grande admiracion, i esto en alquitaras de Conventos i las de mas vulgares, que eran dignos de grandes castigos. Por donde se vee bien claro quan en pro fuera que todos usaran alquitaras estañadas o de estaño, las capas hechas de pedaços quales algunos amigos las han hecho por mi orden, las caçuelas como avemos dicho de debaxo i quando sean de cobre no importa cosa alguna, pues no puede subir a lo alto mal sabor ni cardenillo, como avemos probado antes» ${ }^{67}$.

Termina este punto declarando que los boticarios cordobeses y jienenses continúan destilando en alquitaras de plomo y, para no incumplir del todo la pragmática de Valles, hacen un par de redomas por alambiques de evaporación.

El punto cuarto, menos centrado en el ataque a la medida de Valles, consiste en un alegato de la práctica destilatoria, de la que Castro Medinilla es un buen conocedor. Las numerosas consideraciones sobre la destilación directa y el baño María, derivadas de su práctica del arte, terminan con una defensa de esta técnica farmacéutica frente a todos aquellos que, por una inadecuada práctica, la atacan

«Los fundamentos no son ni han sido hasta oi entendidos, mirandole sin passion $\mathrm{i}$ entendiendo bien estos discursos hallara el benigno lector ser esta distilacion la verdadera con doctrina solida fundada en la verdad i razones naturales, i philosophicas con la verdadera experiencia, qual con mirar las distilaciones que se hacen por los Chimicos, i tomando otra qualquiera ierba, e infundirla despues de serca, i hacer su distilacion, vendra a el verdadero conocimiento el que de esto aia de juzgar, pues injusta cosa será que uno aia de dar su parecer en cosa que consiste juntamente en mi buen discurso, o con experiencia de practica; i mas si fuere remitido a vista i parecer de medico que no supiere de distilaciones, juzgara solo por parecer Physico i argumentos, que faltandole la manifactura es en vano, pues para esto es necessario sea Chimico, como conviene que lo sea todo Medico» ${ }^{68}$.

67 BN, mss. 4250 , ff. $33 v^{\circ}-34$.

68 BN, mss. 4250 , ff. $63 \mathrm{v}^{\mathrm{o}}-64$. 
Al igual que hizo Diego de Santiago veinte años antes, cuando publicaba el primer tratado de destilación escrito en castellano ${ }^{69}$, Castro Medinilla presenta los destilatorios por él diseñados, en los cuales

«se distilassen licores tales, quales convenian a lo que los Medicos pretenden, i en modo facil, para que los pobres gocen perfectas aguas distiladas i con menos costa» ${ }^{70}$.

Descritos y dibujados en el manuscrito ${ }^{71}$, son dos: un alambique grande, formado por olla con cuello, cabeza o capitel y refrigerante, destinado a la extracción de todo tipo de licores; y un alambique pequeño, formado por una olla con cuello y una cabeza o capitel. Su utilidad, también descrita por Castro, es evidente: mientras que el alambique grande se ha de utilizar en destilaciones de gran magnitud, el alambique pequeño es para uso diario o para destilaciones en poca cantidad.

\section{INFLUENCIA DE VALLES A LO LARGO DEL SIGLO XVII}

La ordenanza de Francisco Valles fue objeto de comentario en algunos de los principales autores farmacéuticos del siglo XVII. Entre otros, destacan Juan del Castillo, Fray Esteban de Villa, Pedro Gutiérrez de Arévalo o Jerónimo Pardo.

Juan del Castillo, destilador gaditano de origen francés, formado en la botica de San Lorenzo de El Escorial, es el autor de una destacada farmacopea que, sin ser oficial, ofrece una interesante visión del estado de la práctica farmacéutica en las primeras décadas del siglo XVII ${ }^{72}$. Como era habitual en este tipo de textos, dedicó un capítulo final a pesas y medidas ${ }^{73}$ donde, sin mencionar a Valles ni su ordenanza, resaltaba el error de aquellos que seguían el sistema salernitano insistiendo, una vez más, en la problemática de que cada provincia y comarca tuviera su propio sistema de medidas.

69 SAnTIAGo, D. (1598), Arte Separatoria y modo de apartar todos los licores, que se sacan por via de destilacion: para que las medicinas obren con mayor virtud y presteza, Sevilla, Francisco Pérez.

70 BN, mss. 4250, fol. 49.

71 BN, mss. 4250, ff. 94-95.

72 CASTILlO, J. (1622), Pharmacopea: universa medicamenta in officinis pharmaceuticis usitata complectens [et] explicans, Gadibus, apud Ioannem de Borja.

73 Tractado de los pessos, y medidas usuales, ff. 328-335. 
Más influyente, sin duda alguna, es el Examen de Boticarios ${ }^{74}$ de Fray Esteban Villa, benedictino regente de la botica del Hospital de San Juan de Burgos. En el capítulo primero recogía todos los tratados que, por su importancia, eran indispensables para el boticario, desde la antigüedad hasta el mismo siglo XVII, dedicando dos puntos a los autores que escribieron sobre destilación ${ }^{75} \mathrm{y}$ sobre pesas y medidas ${ }^{76}$. A este último tema dedica un capítulo completo al final de la obra ${ }^{77}$, donde se muestra de acuerdo con la ordenanza de Valles.

Por su parte, el boticario madrileño Pedro Gutiérrez de Arévalo, en su Práctica de boticarios $^{78}$, trata el tema de la destilación, aunque sin referirse explícitamente a la obra de Valles:

«Pues querer dezir, que en el baño no se consume nada de la humedad de lo que se cuece, sino el agua del baño, es falso, como lo vera quien con la experiencia quisiere provarlo, y sino responda. Todas las veces que destilamos en baño qualquier cosa, no sale el vapor arriba de la cosa que queremos destilar, claro está, y sino estuviese puesta la cabeça del alambique, que haze que el vapor se convierta en licor que se destila (y no todo) todo lo que subiesse arriba, no seria resoluble? Claro esta, que esso es ser elixable, luego provado esta, que solo con el baño se resuelve, quanto y mas con una hora de cocimiento, que ha de ser de muchos grados mas de calor que el baño» ${ }^{79}$.

La malignidad de los metales como materia prima para la elaboración de recipientes domésticos quedó de manifiesto en numerosos tratados dedicados a la forma más correcta de beber el agua, que tanta fama alcanzarán desde mediados del siglo XVI. En ellos se mencionan los problemas derivados de una incorrecta utilización de los recipientes metálicos, no sólo en la destila-

74 Burgos, Pedro de Huydobro, 1632.

75 «De destilaciones muchos, pero los mas conocidos, Evonimo, Philipo Ulstadio, Ulvekherio, y en Romance Diego de Santiago el Arte Separatoria», VILLA (1632), p. 9. Se trata de una de las escasas referencias al destilador Diego de Santiago en la bibliografía española del XVII.

76 «Galeno, Medico de Neron, en la quarta y quinta clase de sus obras de Simples (...) Serapion de Simples, 7. Lib. (...) Saladino, un Compendio de Compositione (...) Iacobo Silvio, una Pharmacopea (...), Laurencio Iouberto, una Pharmacopea fue Frances (...) Iacobo de Manlius, el libro llamado Luminare Maius (...) El Collegio de Zaragoza, una Pharmacopea con un tratado de Sinonimos (...) Fernelio, De compositione medicamentorum. El Libro septimo Del Methodus medendi (...) Iuan del Castillo Boticario de Cadiz otra [Pharmacopea]».

77 «De las Pesas y Medidas». VILla (1632), pp. 218-222 vo.

78 Gutiérrez de Arévalo, P. (1634), Práctica de boticarios. Guía de enfermeros. Remedios para pobres, Madrid, María de Quiñones.

79 GutiÉRREZ DE ARÉVALO (1634), pp. 39vº-40. 
ción de aguas artificiales, sino como receptáculos de líquidos y alimentos. La reprobación del uso de recipientes metálicos para las bebidas se repite a lo largo de todo el siglo XVII. Así, el médico Fernando Cardoso condena el uso de aguas que hayan pasado por

«minerales de hierro, de alumbre, de salitre, de açufre, y lo que mas es, las que passan por venas de plata, o de oro; porque vea su castigo la ambiciosa sed de aquellos, que con vana ostentacion trasladan el adorno del habito a la delicia del gusto, pareciendoles, que como luce en lo esterior de sus galas, aprovechara en lo interior de sus venas ${ }^{80}$.

Este aspecto, destacado en la ordenanza de Valles, será el reseñado en la obra del catedrático de método de Valladolid Jerónimo Pardo:

«con justissima causa esta establecida ley en la Nueva Recopilacion, en que se manda a los Boticarios, no den, ni vendan aguas destiladas, de las que fueren para tomar por la boca, sino que sean destiladas por alambique de vidrio. La qual ley juzgo se ordenó, y promulgó a instancia del insigne Dotor Valles, Protomedico General en aquellos tiempos, el qual hizo empeño en probar que las aguas que se toman por la boca, no devian destilarse por alambique de cobre, ni de otro metal, por temer que se les comunica la malignidad que los metales tienen ${ }^{81}$.

Las numerosas polémicas y disputas suscitadas por una norma que, publicada en 1591, sigue siendo objeto de debate medio siglo después nacen, en gran medida, de la falta de un corpus documental y legislativo que estableciese, claramente, los límites de una profesión de indudable importancia dentro del arte de curar: la del preparador de medicamentos.

Las medidas legislativas, limitadas a regular la forma de examen y la visita a boticas, tenían un carácter inequívocamente económico, primaba la cobranza de penas e impuestos sobre la correcta formación del boticario. De esta forma, la adquisición de conocimientos novedosos, la lectura de las últimas publicaciones en materia terapéutica quedaban reducidas a aquellos profesionales verdaderamente interesados, una pequeña elite que alzará la voz en numerosas ocasiones, a lo largo de todo el siglo XVII, con la intención de buscar una mayor preparación entre el colectivo farmacéutico.

80 CARdoso, F. (1637), Utilidades del agua i de la nieve, del bever frio i caliente, Madrid, Viuda de Alonso Martin, p. 38.

81 PARDo, J. (1661), Tratado del vino aguado y agua envinada, sobre el Aforismo 56. de la seccion 7. de Hipocrates, Valladolid, Imprenta de Valdivielso, pp. 119-120. 